Approved for public release; distribution is unlimited

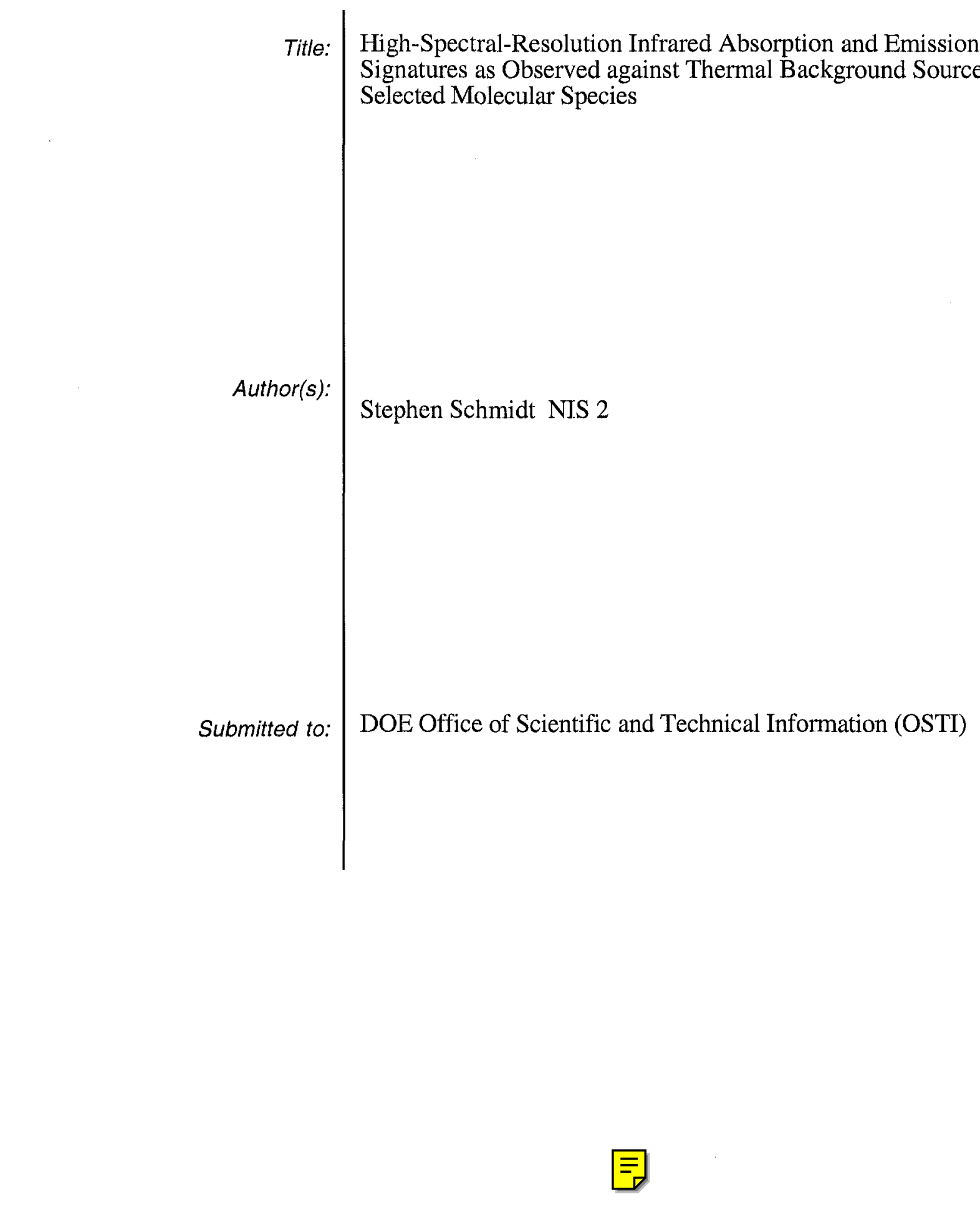

Los Alamos National Laboratory, an affirmative action/equal opportunity employer, is operated by the University of California for the U.S. Department of Energy under contract W-7405-ENG-36. By acceptance of this article, the publisher recognizes that the U.S. Government retains a nonexclusive, royaltyfree license to publish or reproduce the published form of this contribution, or to allow others to do so, for U.S. Government purposes. Los Alamos National Laboratory requests that the publisher identify this article as work performed under the auspices of the U.S. Department of Energy. Los Alamos National Laboratory strongly supports academic freedom and a researcher's right to publish; as an institution, however, the Laboratory does not endorse the viewpoint of a publication or guarantee its technical correctness. 


\title{
High-Spectral-Resolution Infrared Absorption and Emission Signatures as Observed against Thermal Background Sources for Selected Molecular Species
}

\author{
Stephen C. Schmidt*
}

\begin{abstract}
This is the final report of a two-year, Laboratory Directed Research and Development (LDRD) project at Los Alamos National Laboratory (LANL). Scientists and engineers have long been interested in the identification and measurement of concentrations of both major and minor species that are either naturally present or artificially introduced into the atmosphere. Their interests range from molecular species determination for the purpose of understanding basic global atmospheric processes to monitoring effluents from local pollution sources and industrial plants. The purpose of our work has been to study in great detail the absorption/emission spectra in the 8- to $14-\mu \mathrm{m}$ wavelength region of trace gases from plumes emitted into the atmosphere.

We used a technique called line-by-line calculations to make highresolution spectral simulations. The effect of regions that physically differed in pressure, temperature, and constituents was handled by dividing the optical path into "homogeneous" layers and then performing the line-by-line spectral simulations in a layer-by-layer sequence. These calculations included both the relevant trace and naturally occurring atmospheric molecular species, thermal background sources (including those whose emissivity and reflectivity vary with wave number), thermal downwelling, aerosols, and convolution with appropriate instrument functions.

We used calculated spectra to demonstrate that remote sensing can be an effective technique for detecting trace species in industrial plumes. Two applications considered were: (1) carbon dioxide, methane, and nitrous oxide in an electrical power plant plume; and (2) acetone, tetrachloroethylene, and methyl ethyl ketone as solvents that might appear in a reprocessing plant plume.

We also performed spectral simulations of measured volcano plume and adjacent sky background spectra for Mt. Popocatepetl near Mexico City. We were actually able to detect, and measure, in the plume intermittent increased levels of carbon dioxide, which heretofore were only suspected. The enhanced carbon dioxide levels were predicted because $\mathrm{Mt}$. Popocatepetl, different from most volcanos, sets over a layer of limestone deep beneath the earth's surface
\end{abstract}

*Principal Investigator, email: scs@lanl.gov 


\section{Background and Research Objectives}

The identification and measurement of concentrations of both major and minor species naturally present and artificially introduced into the atmosphere have long been subjects of scientific and engineering focus. Interest in this subject ranges from molecular species determination for the purpose of understanding basic global atmospheric processes to monitoring effluents from local pollution sources and industrial plants. Often the nature of the problem under investigation precludes direct in-situ measurements and remote sensing methods must be used. One of the most successful remote sensing techniques is that of obtaining spectral signatures characteristic of the subject molecules (e.g. using Fouriertransform spectrometry) and then using quantitative analysis to identify either the absence or presence of particular species, and in many instances to quantitatively determine concentrations.

Such methods require detailed study of the emission/absorption spectra of the subject molecules as viewed against a thermal background and the concomitant calculations of the effect of the intervening environment on these spectra. The purpose of this work has been two-fold: 1) to study and characterize [in great detail and high resolution over the 8 to 14 micron wavelength region] the absorption/emission spectra of trace gases in time-varying plumes comprised of other more abundant absorbing/emitting molecules, and 2) to determine the alteration and degradation of these spectra by the absorption/emission and scattering characteristics of naturally present atmospheric constituents such as ozone and water vapor.

\section{Importance to LANL's Science and Technology Base and National R\&D Needs}

Detection and quantitative identification of trace gases in plumes are of considerable interest because of their appearance as effluents of particular types of industrial processing plants. A remote sensing measurement technique of these chemical species is highly desirable for governmental monitoring considerations and in particular can contribute significantly to Los Alamos's proliferation detection studies. For sophisticated remote sensing applications, the spectral simulations obtained in this study can serve as spectral sources for determining the signal-to-noise and signal-to-clutter ratios used for the determination of minimum detectable quantities of trace gases. 


\section{Scientific Approach and Accomplishments}

High-resolution spectral calculations were accomplished using a technique called line-by-line calculations. The effect of regions physically differing in pressure, temperature, and constituents was handled by dividing the optical path into "homogeneous" layers and then performing the line-by-line spectral simulations in a layer-by-layer sequence. All spectrally active molecules, both of interest and background, were included in the calculation. The net effect is solving the radiative transfer problem for an optical path starting at the thermal background source, passing through the atmospheric path between the background and the region of interest, through the region of interest (e.g. a plume), and then through the remaining atmospheric path to a detector.

A line-by-line, high-resolution, spectral simulation code, FASCODE, has been identified and was used to compute successfully the spectra for several remote sensing applications. These calculations included both the relevant trace and naturally occurring atmospheric molecular species included in the HITRAN spectral parameters data base, thermal background sources including those whose emissivity (and reflectivity) vary with wave-number, thermal down-welling, aerosols, and convolution with appropriate instrument functions. Spectral line parameters for several solvent molecules not included in the HITRAN molecular database have been installed in a pseudo line database for use in conjunction with HTTRAN as source files for FASCODE. These steps required both corrections and additions to the FASCODE coding.

Figure 1 shows a comparison between similar calculations of atmospheric transmissivity using MODTRAN 3.5, a code routinely used in our group, and FASCODE for a limited spectral range that includes part of the ozone band near $1000 \mathrm{~cm}^{-1}$. The upper panel gives results for both codes at a spectral resolution of $1.0 \mathrm{~cm}^{-1}$, the maximum possible for MODTRAN 3.5. In the lower panel an increase in resolution to $0.1 \mathrm{~cm}^{-1}$ for the FASCODE simulation reveals many spectral features that are not observable at lesser resolution. Results of application of our method to several remote sensing scenarious are described in the following paragraphs.

\section{A. Industrial Plumes}

Synthetic spectra calculated with FASCODE were used to demonstrate that remote sensing, both looking up from the surface using the sky and atmospheric radiance as a background and looking down from high altitude with the earth's surface and man-made features as backgrounds, can be an effective technique for detecting trace species in industrial plumes. Two applications were considered: carbon dioxide $\left(\mathrm{CO}_{2}\right)$, methane $\left(\mathrm{CH}_{4}\right)$, and nitrous oxide $\left(\mathrm{N}_{2} \mathrm{O}\right)$ observations in an electrical power plant plume and the 
detection of acetone $\left(\mathrm{C}_{3} \mathrm{H}_{6} \mathrm{O}\right)$, tetrachloroethylene or TCE $\left(\mathrm{C}_{2} \mathrm{Cl}_{4}\right)$, and methyl ethyl ketone or $\mathrm{MEK}\left(\mathrm{C}_{4} \mathrm{H}_{8} \mathrm{O}\right)$ as solvents that might appear in a reprocessing plant plume. The scenarios modeled are described in Table 1 and are summarized in the following discussion.

Power Plant Plume. Simulations of the spectra expected from the subject gases in a power plant plume were performed for two wave-number regions, that from 700 to $1400 \mathrm{~cm}^{-1}$ called the $10 \mu$ region and that from 2000 to $3000 \mathrm{~cm}^{-1}$ called the $4 \mu$ region. Figures 2 and 3 show the spectra for these regions when the plume is observed from the surface at an angle of $20^{\circ}$ from the horizon. The bottom traces are the radiances of the atmosphere and sky background without a plume in the line of sight. The introduction of the plume results in the spectra given by the top lines in the figures. The heavily shaded areas between the traces depicts the increased radiance at each wave-number resulting primarily from the trace species or warm water vapor in the plume. For these simulations the temperature of the plume, $30^{\circ} \mathrm{C}$, was greater than that of the atmosphere or sky background; therefore the effect of the plume was always to increase the radiance at each wave-number. If the plume had been colder than the atmosphere, not a likely situation for a power plant, the species would have appeared as absorption instead of emission features in the spectra.

Figures 4 and 5 show spectral simulations of the $10 \mu$ and $4 \mu$ regions for a much warmer, $70^{\circ} \mathrm{C}$, plume viewed against soil represented by a surface emissivity of 0.97 or a highly reflecting background such as a metal roof represented by a surface emissivity of 0.56 . The bottom and top traces connote as above, simulations without and with the plume present.

The prominent features in the spectra near $1050 \mathrm{~cm}^{-1}$ and $2300 \mathrm{~cm}^{-1}$ result from absorption or emission by atmospheric ozone and carbon dioxide respectively. For the 4- $\mu$ region, the increased, almost spike-like emission intensity near the edges of the features are from warm carbon dioxide in the plume. These calculations show that strong carbon dioxide discharge in a plume would be readily observable in the 4- $\mu$ region, and with a low surface emissivity, in the $10-\mu$ region. Detection for scenarios with a surface emissivity near one at $10 \mu$ would be more difficult. Carbon dioxide also shows strong emission near $760 \mathrm{~cm}^{-1}$, but use of this feature would depend on a good interpretation of the atmospheric absorption features in this region. Nitrous oxide features are observed for both spectral regions with the most significant offering the greatest possibility for detection, which is that 
near $2160 \mathrm{~cm}^{-1}$. Detection of methane would be made using the feature near $1250 \mathrm{~cm}^{-1}$; however this again would depend on a good interpretation of the atmospheric absorption features at these wave numbers.

Processing Plant Plume. For the solvents, only the $10-\mu$ region was considered because acetone, TCE, and MEK do not exhibit absorption features in the 4- $\mu$ region of the spectrum. Figures 6,7 , and 8 show, along with the absorption or emission from atmospheric ozone near $1050 \mathrm{~cm}^{-1}$, prominent features from all three solvents. The concentration of TCE used for the calculation is sufficient to saturate the spectrum. When the plume is viewed against the atmosphere/sky background, Figure 6, or against the high emissivity soil background, tops of Figures 7 and 8 , acetone, MEK, and the weaker TCE feature, appear in the spectral gaps between stronger water vapor lines. For the scene of a cold plume, $20^{\circ} \mathrm{C}$, viewed against a warmer, $40^{\circ} \mathrm{C}$ surface background, Figure 8 , the spectral features are observed in absorption for high surface emissivity, 0.97 , but in emission when the emissivity assumes a value, 0.56 , more characteristic of a reflecting surface. Again, as for the power plant scenario, down looking detection of trace species in a plume becomes easier as the background emissivity decreases because the total radiance emitted by the surface at each wave number decreases compared to the radiance of the species.

The high-resolution, absolute magnitude simulation of the radiative transport through the plume and atmospheric layers calculated using FASCODE renders these and many other features of the different spectra easily visible. This brief summary illustrates the capability of FASCODE to readily simulate, both for instrument design needs and for data analysis, experimental observations.

Atmospheric Transmissivity. Calculations of the atmospheric transmissivity with and without different plume species in the line of sight have been performed in support of the development of techniques to analyze data from multispectral imaging instruments. The results of these simulations are used to produce "matched filters" capable of identifying particular species in the atmosphere or as constituents of a plume. The top curve in Figure 9 gives the atmospheric transmissivity at $0.1 \mathrm{~cm}^{-1}$ spectral resolution for no plume. The addition of a plume as described in the figure, reduces the transmissivity to that given by the lower line. The shaded area between the lines represents the decrease in transmission resulting from the trace species. This is more clearly shown in Figure 10 as the difference between the two simulations. The spectral locations for the three trace species are given approximately by their molecular identification. In Figure 10 all the spectral lines not 
associated with the shaded areas shown for sulfur hexafluoride ( $\left.\mathrm{SF}_{6}\right)$ or sulfur dioxide $\left(\mathrm{SO}_{2}\right)$ are ammonia $\left(\mathrm{NH}_{4}\right)$ features. Similar transmissivity calculations have been done with acetone $\left(\mathrm{C}_{3} \mathrm{H}_{6} \mathrm{O}\right)$, tetrachloroethylene $\left(\mathrm{C}_{2} \mathrm{Cl}_{4}\right)$, methyl ethyl ketone $\left(\mathrm{C}_{4} \mathrm{H}_{8} \mathrm{O}\right)$, and trichloroethylene $\left(\mathrm{C}_{2} \mathrm{HCl}_{3}\right)$ as plume constituents and also at a resolution of $0.01 \mathrm{~cm}^{-1}$ for midlatitude summer and 1976 U.S. Standard atmospheres.

Stack Discharge. FASCODE was used to simulate SEBASS experimental spectra taken from an aircraft of the stack discharge from the Page, AZ electrical generating station. The spectra for two pixels, one that included the discharge plume viewed against a metal roof and a second of a metal roof whose spectral signature closely resembled that of the first pixel, were chosen for analysis. These spectra are shown in Figure 11 as Data, Plume Pixel, \#37-775 and Data, Reference Pixel, \#49-942 respectively. The spectrum from the Plume Pixel shows a strong feature near $950 \mathrm{~cm}^{-1}$ corresponding to the sulfur hexafluoride $\left(\mathrm{SF}_{6}\right)$ that was released as a trace species in the plume. Also noted on the figure are strong spectral features from water $\left(\mathrm{H}_{2} \mathrm{O}\right)$ and carbon dioxide $\left(\mathrm{CO}_{2}\right)$. The synthetic spectra were calculated using a midlatitude summer atmosphere with the changes given in the figure. The addition of $3 \mathrm{ppm}$ of sulfur hexafluoride to the plume layer for the calculation matched the experimental observation.

A small amount of sulfur dioxide ( $\mathrm{SO}_{2}$ ) was added to the atmosphere in an attempt to better match the experimental spectra from 1100 to $1200 \mathrm{~cm}^{-1}$; however, it is believed that this is not the correct thing to do. The simulations do not match the data well in the spectral region from 950 to $1150 \mathrm{~cm}^{-1}$. Several combinations of surface temperature, surface emissivity, and atmospheric constituents, including additional ozone (O3) did not improve the match. A gray-body, uniform surface emissivity was used for all calculations. It is believed that an emissivity that varies with wave number is the reason for the discrepancy and that further simulations require better modeling of the surface emissivity. Without direct measurements of the wave-number dependence of the emissivity for the metal roof, it is difficult to improve the match between the data and the simulations.

B. HIRIS Instrument Tests

Several tests of the HIRIS instrument were conducted at the Nevada Test Site during September of 1997. One of the tests was the release, from a hot stack, of acetone $\left(\mathrm{C}_{3} \mathrm{H}_{6} \mathrm{O}\right)$, tetrachloroethylene or TCE $\left(\mathrm{C}_{2} \mathrm{Cl}_{4}\right)$, methyl ethyl ketone or $\mathrm{MEK}\left(\mathrm{C}_{4} \mathrm{H}_{8} \mathrm{O}\right)$, and dichloromethane or DCM $\left(\mathrm{CH}_{2} \mathrm{Cl}_{2}\right)$ at flow rates of $144 \mathrm{lb} / \mathrm{hr}, 120 \mathrm{lb} / \mathrm{hr}, 16 \mathrm{lb} / \mathrm{hr}$, and 12 $\mathrm{lb} / \mathrm{hr}$, respectively. The HIRIS instrument was positioned to observe the approximately 4- 
$\mathrm{m}$-diameter plume from a distance of $1.4 \mathrm{~km}$ with a soil/rock background approximately 5.6 $\mathrm{km}$ beyond the plume. FASCODE was used to simulate the experimental spectra collected.

The background spectrum shown in Figure 12, to be used as a reference for spectra taken of the plume, was obtained by averaging the spectra from 113 pixel regions with pixels located both above and below the plume. The FASCODE simulation is also given for the path conditions stated in the figure. It is seen that the calculation matches the data reasonably well except for three spectral regions: one near $800 \mathrm{~cm}^{-1}$, one near $920 \mathrm{~cm}^{-1}$, and one extending from 1000 to $1170 \mathrm{~cm}^{-1}$.

These disagreements can be seen more clearly in Figure 13, a plot of brightness temperature, rather than radiance, versus wave number. An unsuccessful attempt was made to make the simulation match the data more closely in the 1000 to $1170 \mathrm{~cm}^{-1}$ region by changing atmospheric path parameters and the background emissivity using values thought to better represent the soil/rock surface. It was concluded the before attempting to explore further changes in the background emissivity, it is necessary to verify the HIRIS calibration. This has been done for recent classified data. For these comparisons the calculations matched the data very well.

The disagreement at $920 \mathrm{~cm}^{-1}$ is thought to result from limestone in the background material. Because the instrument calibration was not verified, no effort was made to determine a surface emissivity that better represents limestone or to determine possible reasons for the disagreement near $800 \mathrm{~cm}^{-1}$. Also, for more recent data these disagreements do not exist.

Synthetic spectra, using the trace species concentrations given in Figure 14, were calculated for comparisons with the average spectra from two plume regions: 9 pixel areas centered at image locations 71-58 and 95-58. The concentrations were chosen to approximately match the relative amounts for the flow rates given above. For TCE, with spectral features near $800 \mathrm{~cm}^{-1}$ and $920 \mathrm{~cm}^{-1}$, the data were matched using a plume temperature of $306.5^{\circ} \mathrm{K}$ for location $95-58$, nearer the stack, and $304.0^{\circ} \mathrm{K}$ for location 71 58. At these temperatures the radiances for acetone and MEK, with bands near $1175 \mathrm{~cm}^{-1}$ and $1225 \mathrm{~cm}^{-1}$ respectively, were considerably underestimated. Increasing the concentrations of these gases would yield much better agreement with the data. Because of the calibration uncertainty, lack of knowledge of the background surface characteristics, and small species concentration, a spectral signature near $750 \mathrm{~cm}^{-1}$, that would indicate DCM in the plume, was not apparent. As was the case for the background spectrum, the discrepancies shown in Figure 14 between the experimental results and the simulations for 
the region from 1000 to $1170 \mathrm{~cm}^{-1}$ requires further consideration of the calibration and the background surface emissivity.

\section{Volcanic Plumes}

Midrange infrared volcano plume and adjacent sky background spectra have been measured for Mt. Popocatepetl near Mexico City. Figure 15 shows the sky background spectrum and FASCODE simulations using a tropical atmosphere with a $25 \%$ increase in atmospheric carbon dioxide. The increased carbon dioxide concentration required to match the data is plausible considering the proximity of the site to the polluted atmosphere of Mexico City. The atmospheric temperature was increased about $5 \mathrm{~K}$ above that expected for a tropical atmosphere for a few meters above the surface to match temperature measurements made at the observation location. Several other different conditions were tried in the simulations including an unaltered tropical atmosphere, a tropical atmosphere using measured relative humidities from Mexico City 50 miles away, and a tropical atmosphere using varying amounts of water vapor and carbon dioxide in different combinations. None of these variations improved the agreement with the experimental data.

Figure 15 gives two FASCODE simulations, one with and one without the addition of a small amount of Freon 11 (F11) and Freon 12 (F12) to the tropical atmosphere near an elevation of $18 \mathrm{~km}$. It can be seen from the figure that the addition of $\mathrm{F} 11$ clearly improves the agreement of the calculation with the data near $850 \mathrm{~cm}^{-1}$, and the addition of $\mathrm{F} 12$ provides similar improvement near $920 \mathrm{~cm}^{-1}$ and for the sharp feature at $1161 \mathrm{~cm}^{-1}$. Better agreement between the simulation and the experimental spectrum is also noted near 870 $\mathrm{cm}^{-1}$ and $1090 \mathrm{~cm}^{-1}$ as a consequence of including Freon in the calculation.

Figure 16 shows a sky background spectrum adjacent to the Mt. Popocatepetl plume and a spectrum viewed through the plume; the differences between these two spectra are shown in Figure 17. Examination of the two spectra in Figure 16 shows only a difference near $1150 \mathrm{~cm}^{-1}$ attributed to sulfur dioxide in the plume and a general increase in radiance for all wavelengths thought to be because of aerosol in the plume. The differences depicted in Figure 17 at greater resolution reveal additional features near $792 \mathrm{~cm}^{-1}$ (to be discussed later), $900 \mathrm{~cm}^{-1}$, and $1030 \mathrm{~cm}^{-1}$. Also given in Figure 17 is the difference from two spectra calculated using FASCODE. The plume simulation was performed using the addition constituents given in the figure. As can be seen the calculated difference accounting for increased concentrations of sulfur dioxide, silicon tetrafluoride, and carbon dioxide matches the experimental difference well. The mismatch near $900 \mathrm{~cm}^{-1}$ is thought to be the result of improperly modeling the aerosol in the plume and remains the topic of future work. 
The middle panel of Figure 18 shows an expanded scale view of a small portion between 780 and $840 \mathrm{~cm}^{-1}$ of the difference spectrum given in Figure 17. The structure observed in the spectrum is from water vapor except for the peaked feature near $792 \mathrm{~cm}^{-1}$, which results from a narrow carbon dioxide band. Two simulations are presented: one with no additional carbon dioxide included in the plume and the second with $3.3 \times 10^{5}$ parts per million-meter (ppmm) added. The better match to experimental data of the calculation that includes the additional carbon dioxide is noted. The upper and lower panels of Figure 18 are of spectra that were obtained at different times and show different concentrations of carbon dioxide in the plume. Spectra also are available for which no additional carbon dioxide is observed in the plume. The conclusion from these results is that the volcano is "puffing" carbon dioxide. Although this behavior had been expected by volcanologists because there is a layer of limestone in the earth deep below Mt. Popocatepetl, this is the first observation of this effect.

In addition to the midrange infrared radiance spectra discussed above, transmission spectra of hydrogen chloride $(\mathrm{HCl})$ near $2800 \mathrm{~cm}^{-1}$ and hydrogen fluoride (HF) near 4000 $\mathrm{cm}^{-1}$ were obtained using scattered solar radiation from diffuse clouds as a background light source. These roughly calibrated data are shown for the P-branch of $\mathrm{HCl}$ and the R-branch of HF in the upper and lower panels, respectively, of Figure 19. The optical depth is defined as the negative logarithm of the ratio of the transmission through the plume to the transmission through the atmosphere adjacent to the plume. A first approximation spectral fit using the stated $\mathrm{HCl}$ and $\mathrm{HF}$ concentrations, but that does not account for additional water vapor in the plume, is also shown. Other temperatures were also tried for the calculation in an attempt to determine the actual temperature of the plume gases, but the quality of the data was insufficient to determine the temperature to better than $+/-30 \mathrm{~K}$. Unless better quality data are obtained for comparison with the calculation, it is not known whether or not this situation can be improved. 


\section{Publications}

1. Love, S. P., Schmidt, S. C., Goff, F., Counce, D., Pettit, D., Christenson, B. W., and Siede, C., "Passive Infrared Spectroscopic Remote Sensing of Volcanic Gases: Ground-Based Studies at White Island and Ruapehu, New Zealand and Popocatepetl, Mexico," Remote Sensing of Active Volcanism, P. Mouginis-Mark, J.Crisp, and J. Fink, eds., American Geophysical Union Monograph, to be published 1999.

2. Love, S. P., Schmidt, S. C., Counce, D., Goff, F., Siebe, C., and Delgado, H., "Applicability of Passive Open-Path Infrared Spectroscopy for Volcanic $\mathrm{CO}_{2}$ Monitoring," Special Session V02: In Situ Carbon Dioxide Measurements in High Flux Localities, American Geophysical Union Meeting, San Francisco, CA, December, 1998.

3. Borel, C. C., Briles, S. D., Clodius, W., Villeneuve, P., Schmidt, S. C., and Smith, B. W., "Analysis of HIRIS Hyperspectral Measurements at NTS," poster presented at 5th Annual CALIOPE Interim Technical Review, Los Alamos National Laboratory, Los Alamos, NM, May 5-7, 1998. 
Table 1

\begin{tabular}{|c|c|c|c|}
\hline & \multicolumn{2}{|c|}{$\begin{array}{l}\quad \text { POWER PLANT } \\
10 \mathrm{~m} \text { dia. Plume } \\
\text { Midlatitude Summer Atm. } \\
10 \% \mathrm{CO}_{2}, 300 \mathrm{ppm} \mathrm{CH} 4,300 \mathrm{ppm} \mathrm{N}_{2} \mathrm{O}, 10 \% \mathrm{H}_{2} \mathrm{O} \\
\text { Elevation }=0.933 \mathrm{~km}\end{array}$} & \multirow{2}{*}{$\begin{array}{l}\text { SOLVENTS } \\
10 \mathrm{~m} \text { dia. Plume } \\
\text { Midlatitude Summer Atm. } \\
\text { Elevation }=0.933 \mathrm{~km} \\
700--1400 \mathrm{~cm}^{-1}\end{array}$} \\
\hline Wavenumber Region & $700--1400 \mathrm{~cm}^{-1}$ & $2000--3000 \mathrm{~cm}^{-1}$ & \\
\hline $\begin{array}{l}\text { LOOKING UP } \\
70^{\circ} \text { from Zenith } \\
\text { Sky Background } \\
\end{array}$ & $30^{\circ} \mathrm{C}$ Plume & $30^{\circ} \mathrm{C}$ Plume & $\begin{array}{l}100 \mathrm{ppm} \mathrm{C}_{3} \mathrm{H}_{6} \mathrm{O}, 100 \mathrm{ppm} \mathrm{C}_{2} \mathrm{Cl}_{4}, 100 \mathrm{ppm} \mathrm{C}_{4} \mathrm{H}_{8} \mathrm{O} \\
22^{\circ} \mathrm{C} \text { Plume }\end{array}$ \\
\hline $\begin{array}{l}\text { LOOKING DOWN } \\
\text { From } 18.2 \mathrm{~km} \\
28^{\circ} \text { C Surlace } \\
\varepsilon=0.97(\mathrm{r}=0.03) \\
\varepsilon=0.56(\mathrm{r}=0.44) \\
\end{array}$ & $70^{\circ} \mathrm{C}$ Plume & $70^{\circ} \mathrm{C}$ Plume & $\begin{array}{l}300 \mathrm{ppm} \mathrm{C}_{3} \mathrm{H}_{6} \mathrm{O}, 100 \mathrm{ppm} \mathrm{C}_{2} \mathrm{Cl}_{4}, 300 \mathrm{ppm} \mathrm{C}_{4} \mathrm{H}_{8} \mathrm{O} \\
35^{\circ} \mathrm{C} \text { Plums }\end{array}$ \\
\hline $\begin{array}{l}\text { LOOKING DOWN } \\
\text { From } 18.2 \mathrm{~km} \\
40^{\circ} \text { C Surface } \\
\varepsilon=0.97(\mathrm{r}=0.03) \\
\varepsilon=0.56(\mathrm{r}=0.44)\end{array}$ & & & $\begin{array}{l}300 \mathrm{ppm} \mathrm{C}_{3} \mathrm{H}_{6} \mathrm{O}, 100 \mathrm{ppm}_{2} \mathrm{Cl}_{4}, 300 \mathrm{ppm} \mathrm{C}_{4} \mathrm{H}_{8} \mathrm{O} \\
20^{\circ} \mathrm{C} \text { Plume }\end{array}$ \\
\hline
\end{tabular}


Transmissivity, 0 - $100 \mathrm{~km}$ Path, Tropical Atmosphere
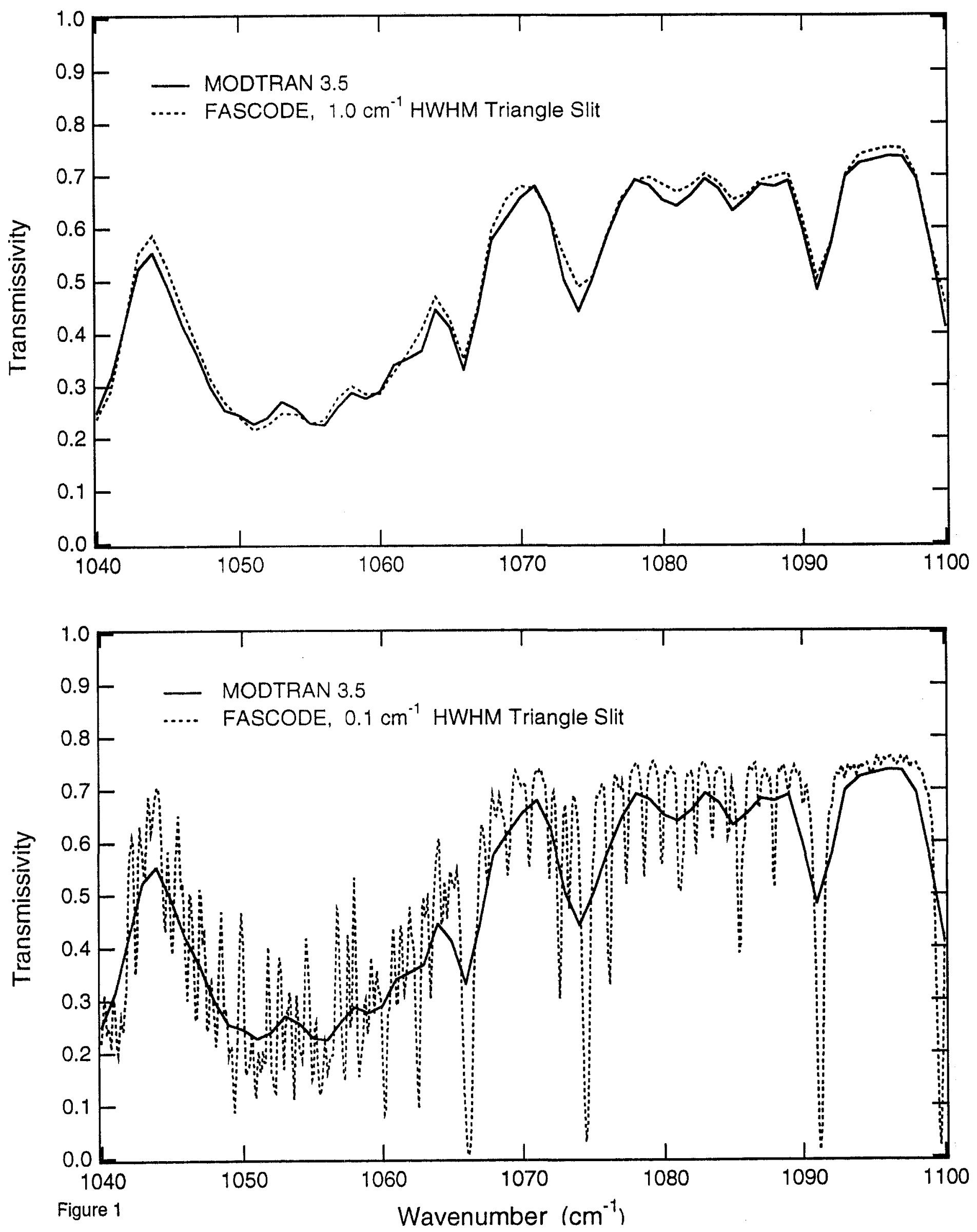


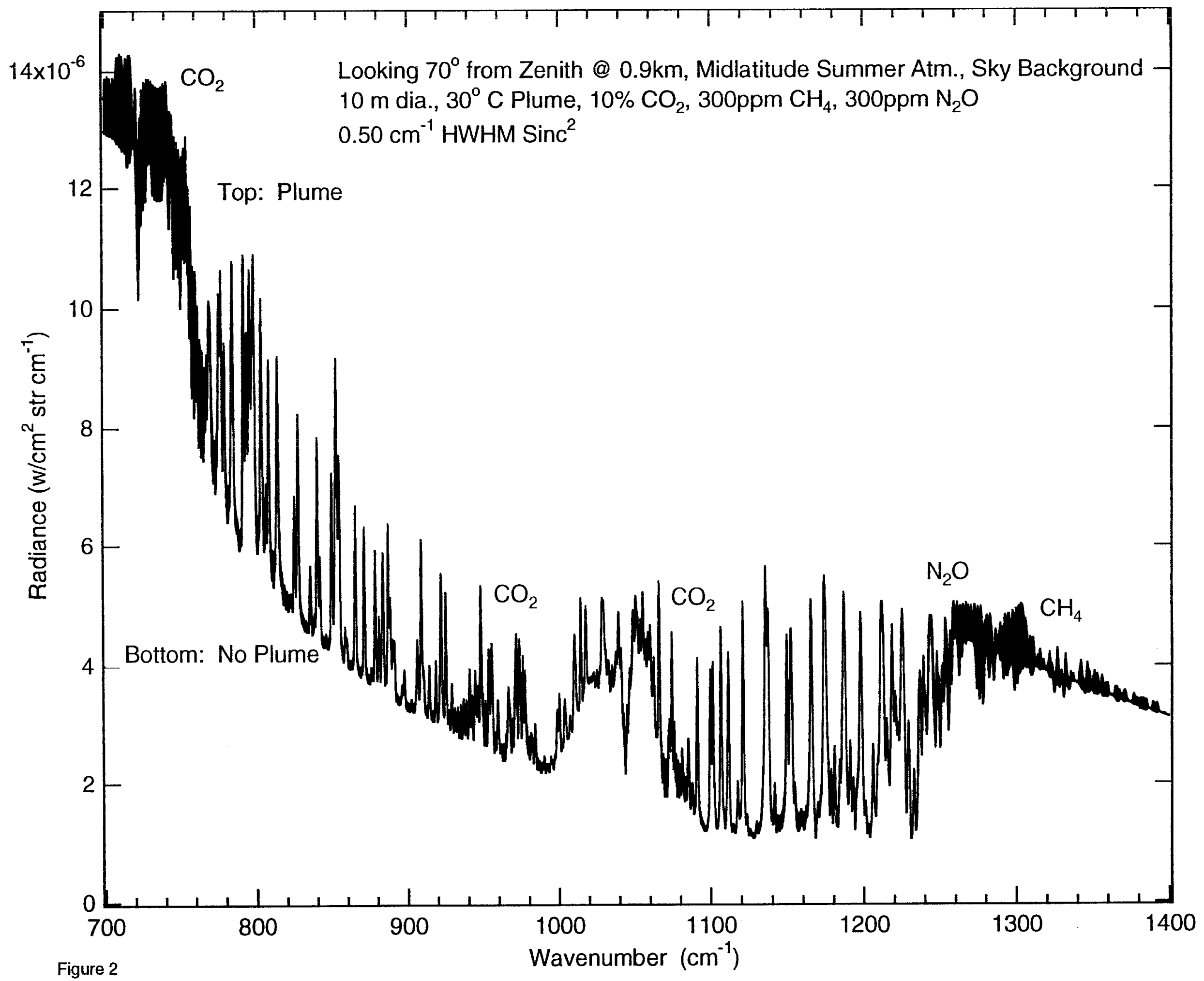




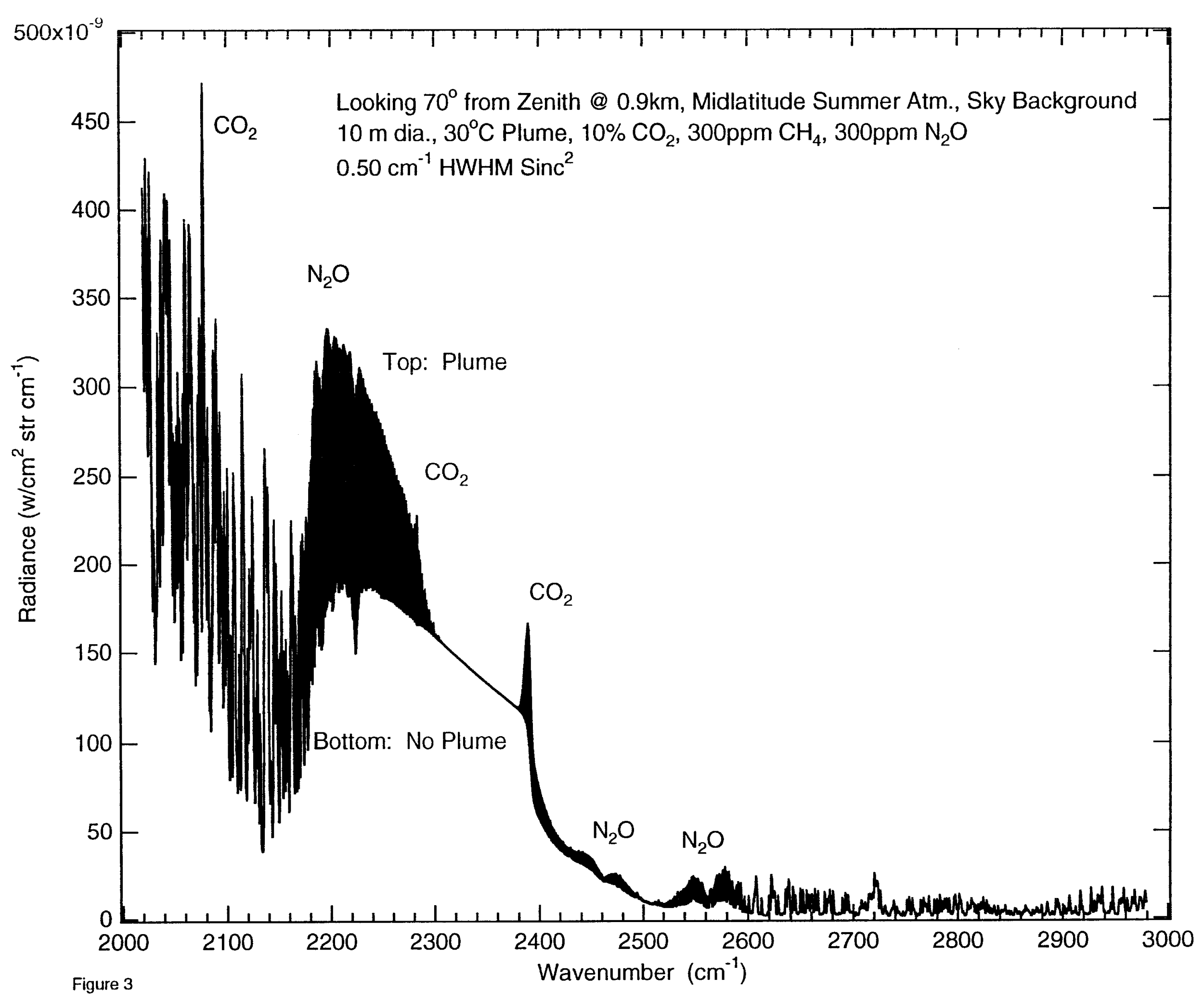


Downlooking $18.2 \mathrm{~km}$ to $0.9 \mathrm{~km}$, Midlatitude Summer Atm., $28^{\circ} \mathrm{C}$ Surface $10 \mathrm{~m}$ dia., $70^{\circ} \mathrm{C}$ Plume, $10 \% \mathrm{CO}_{2}, 300 p p m \mathrm{CH}_{4}, 300 \mathrm{ppm} \mathrm{N}_{2} \mathrm{O}$ $0.5 \mathrm{~cm}^{-1}$ HWHM Sinc ${ }^{2}$
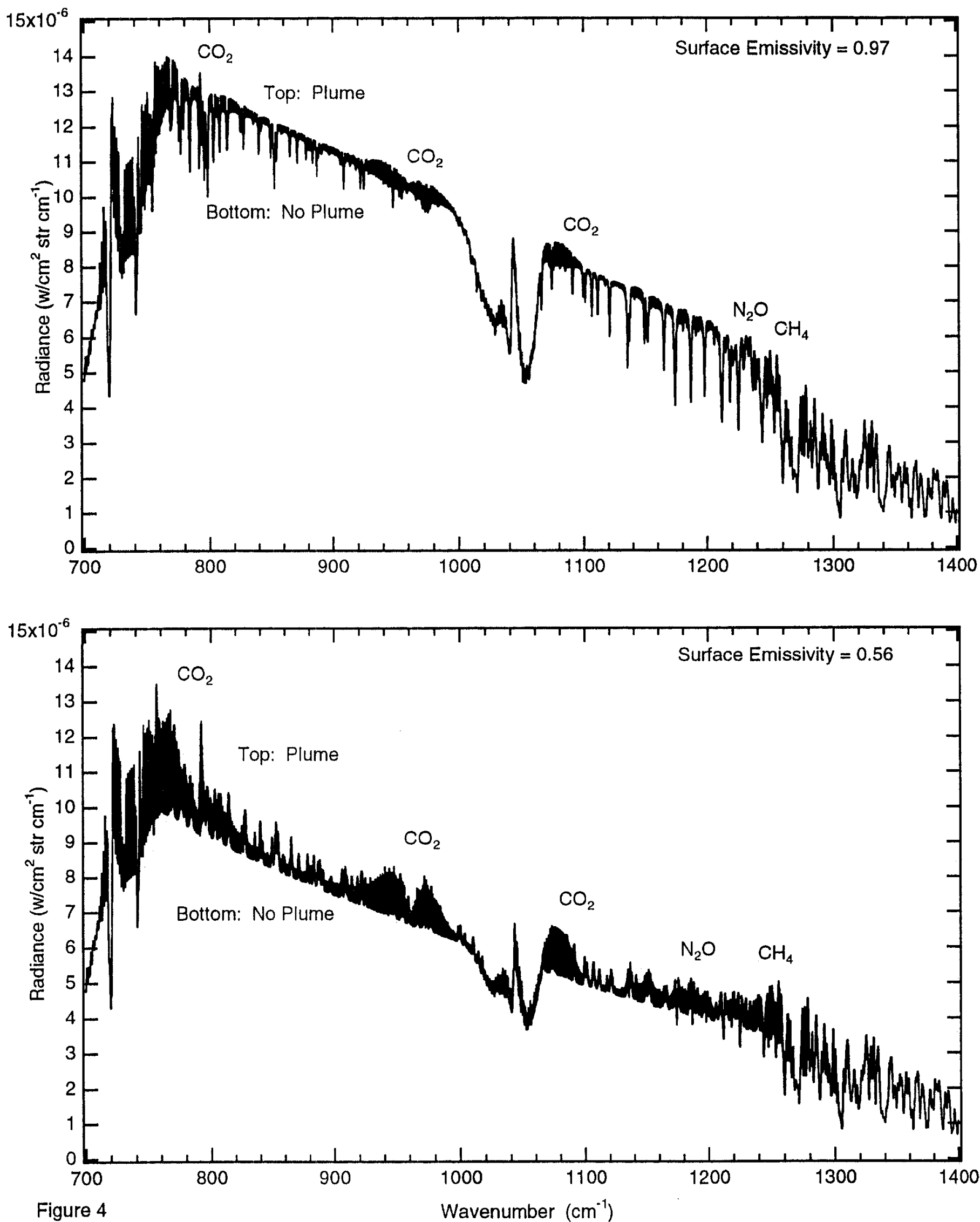
Downlooking $18.2 \mathrm{~km}$ to $0.9 \mathrm{~km}$, Midlatitude Summer Atm., $28^{\circ} \mathrm{C}$ Surface $10 \mathrm{~m}$ dia., $70^{\circ} \mathrm{C}$ Plume, $10 \% \mathrm{CO}_{2}, 300 \mathrm{ppm} \mathrm{CH}_{4}, 300 \mathrm{ppm} \mathrm{N}_{2} \mathrm{O}$ $0.5 \mathrm{~cm}^{-1} \mathrm{HWHM} \operatorname{Sinc}^{2}$
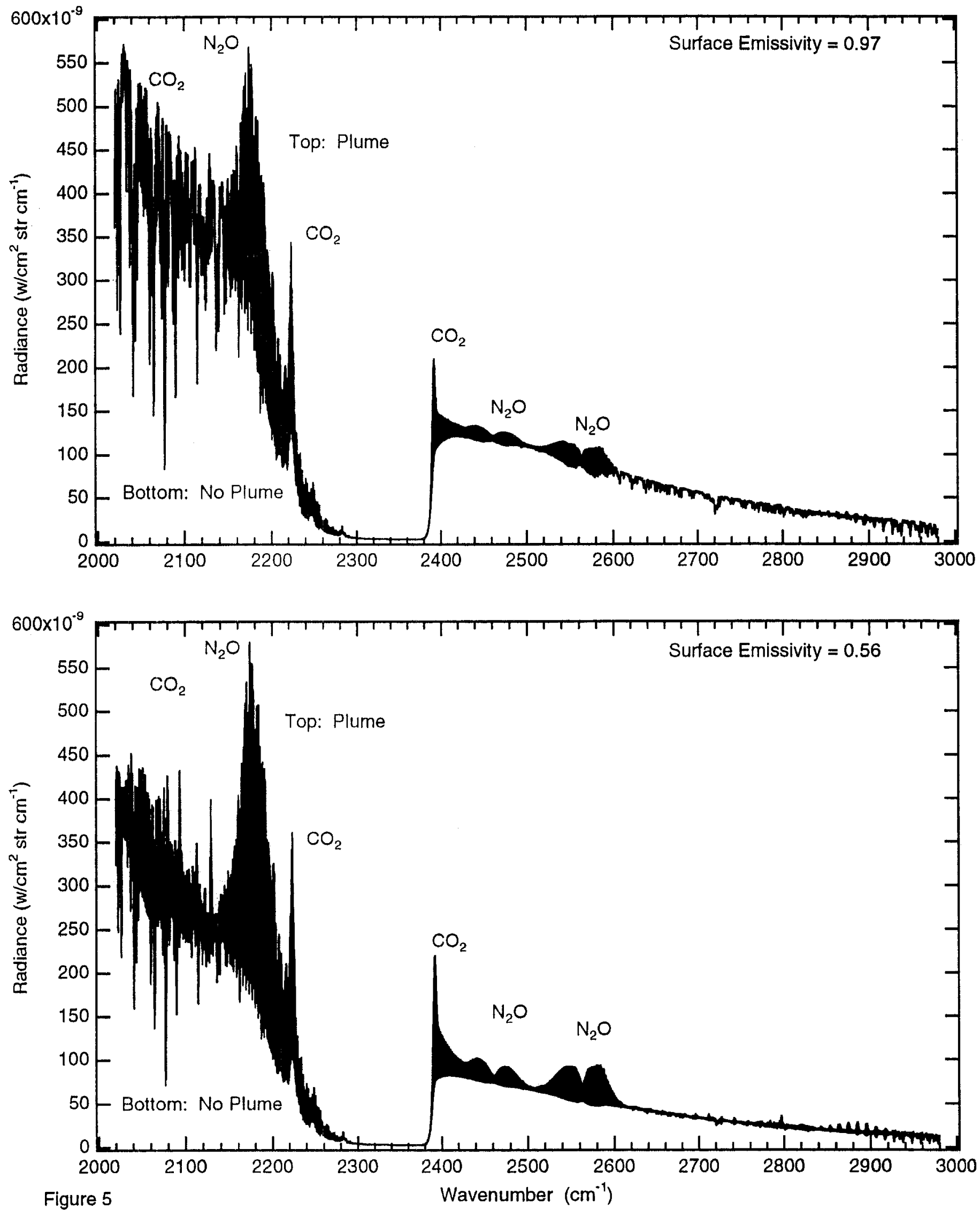


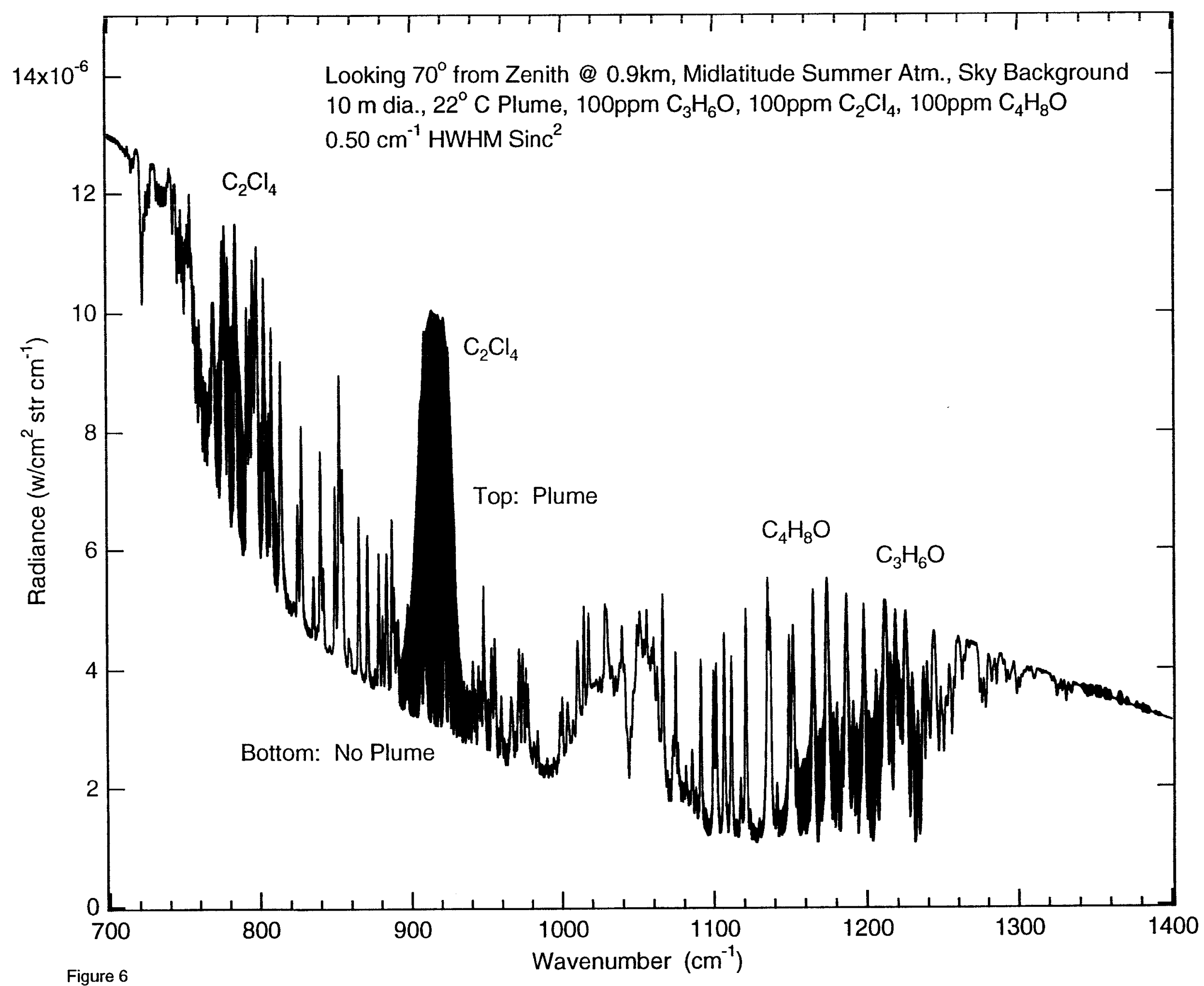


Downlooking $18.2 \mathrm{~km}$ to $0.9 \mathrm{~km}$, Midlatitude Summer Atm., $28^{\circ} \mathrm{C}$ Surface

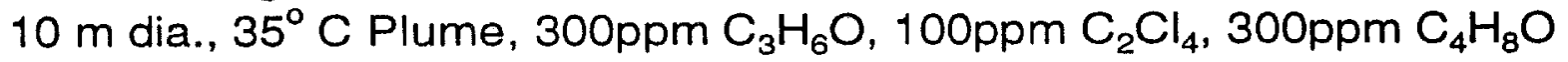
$0.5 \mathrm{~cm}^{-1}$ HWHM Sinc ${ }^{2}$
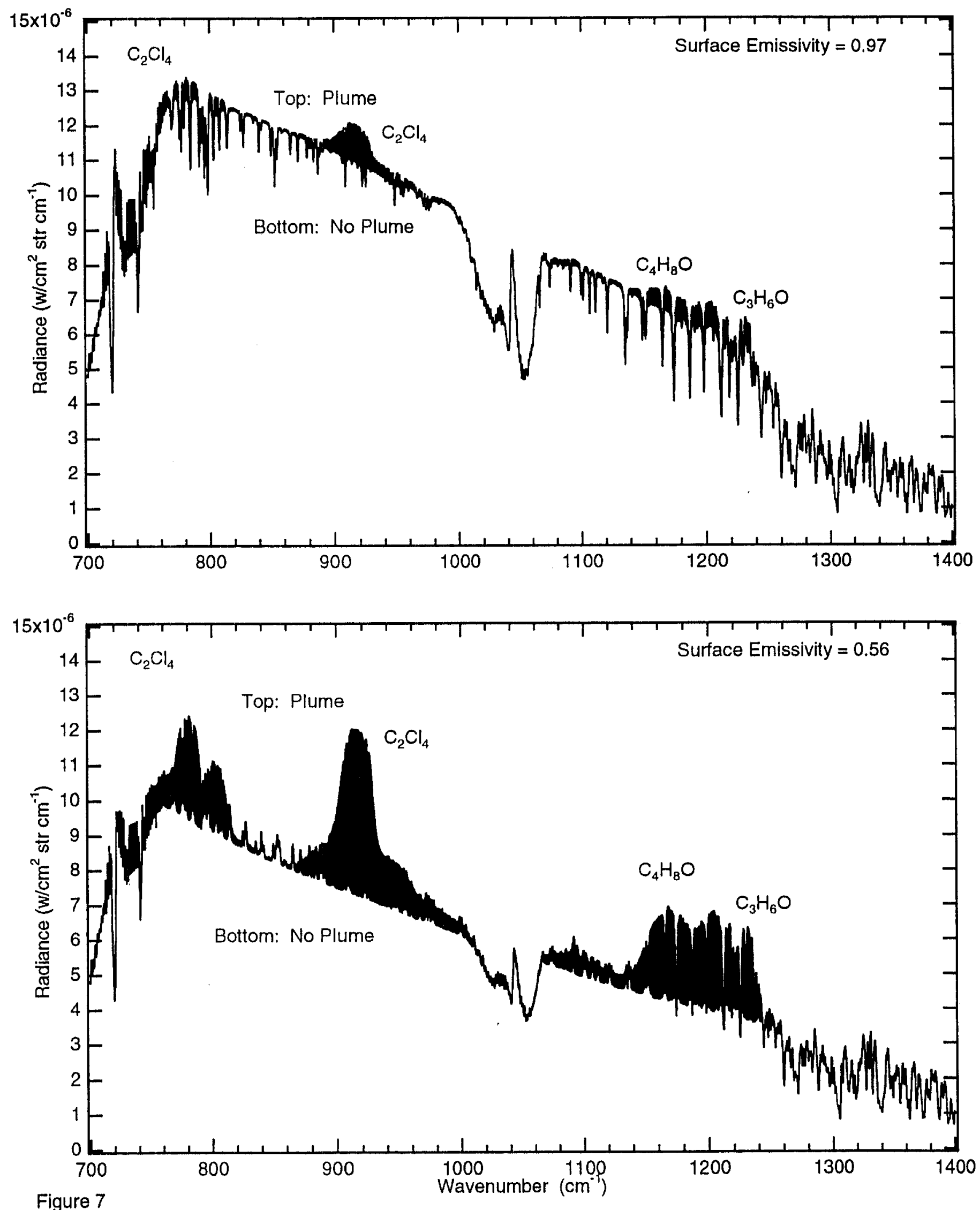
Downlooking $18.2 \mathrm{~km}$ to $0.9 \mathrm{~km}$, Midlatitude Summer Atm., $40^{\circ} \mathrm{C}$ Surface $10 \mathrm{~m}$ dia., $20^{\circ} \mathrm{C}$ Plume, 300ppm $\mathrm{C}_{3} \mathrm{H}_{6} \mathrm{O}$, 100ppm $\mathrm{C}_{2} \mathrm{Cl}_{4}$, 300ppm $\mathrm{C}_{4} \mathrm{H}_{8} \mathrm{O}$ $0.5 \mathrm{~cm}^{-1}$ HWHM Sinc ${ }^{2}$
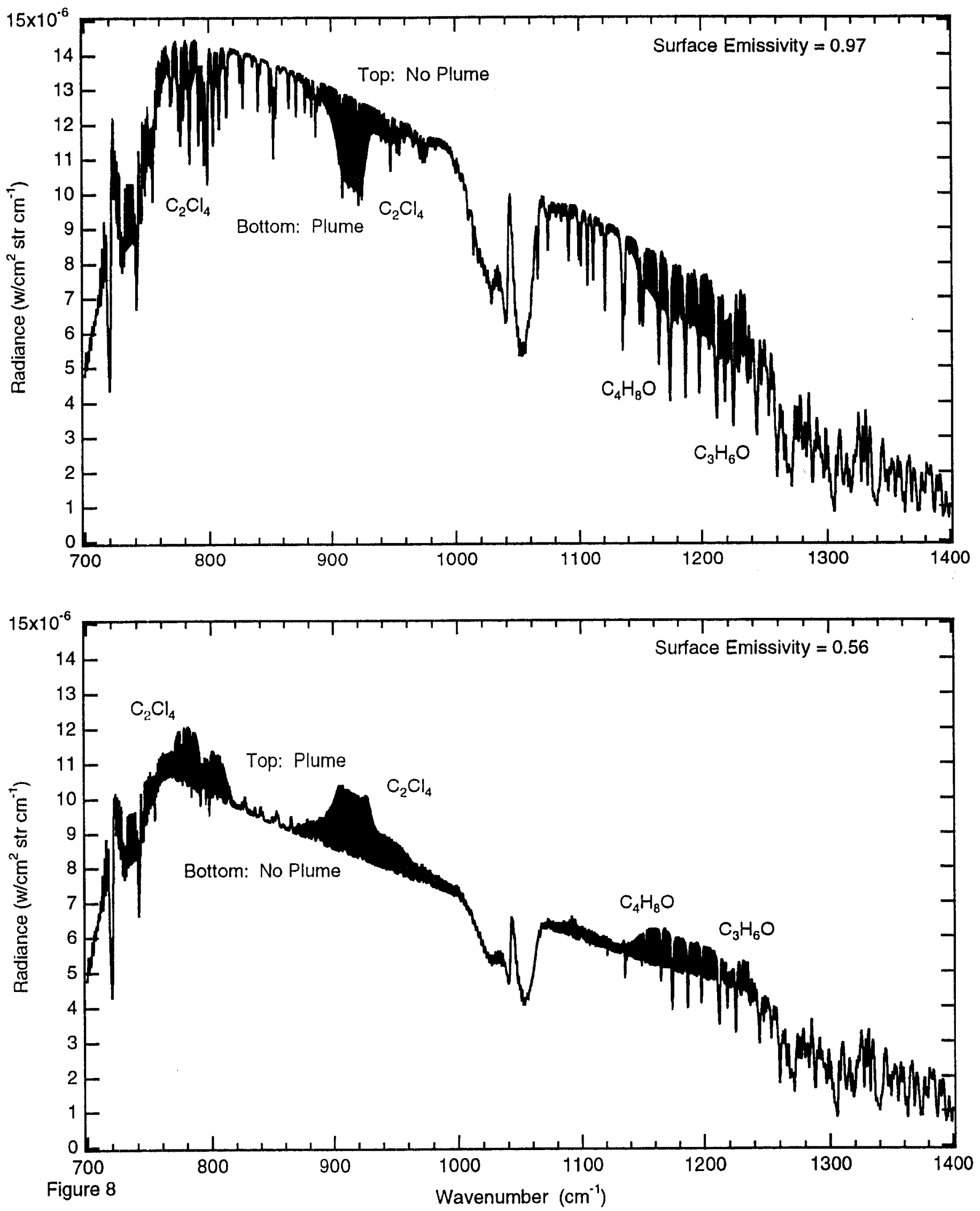


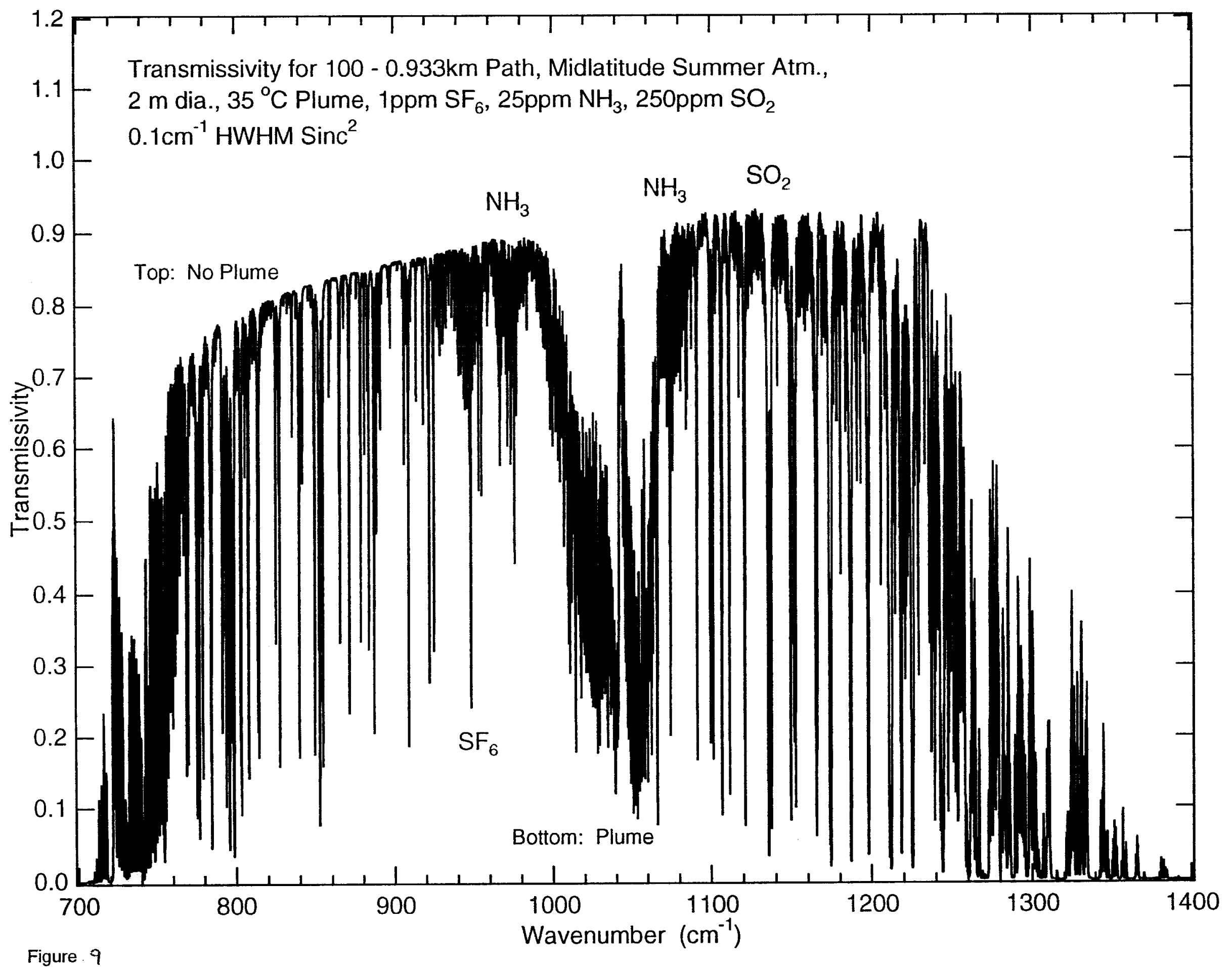




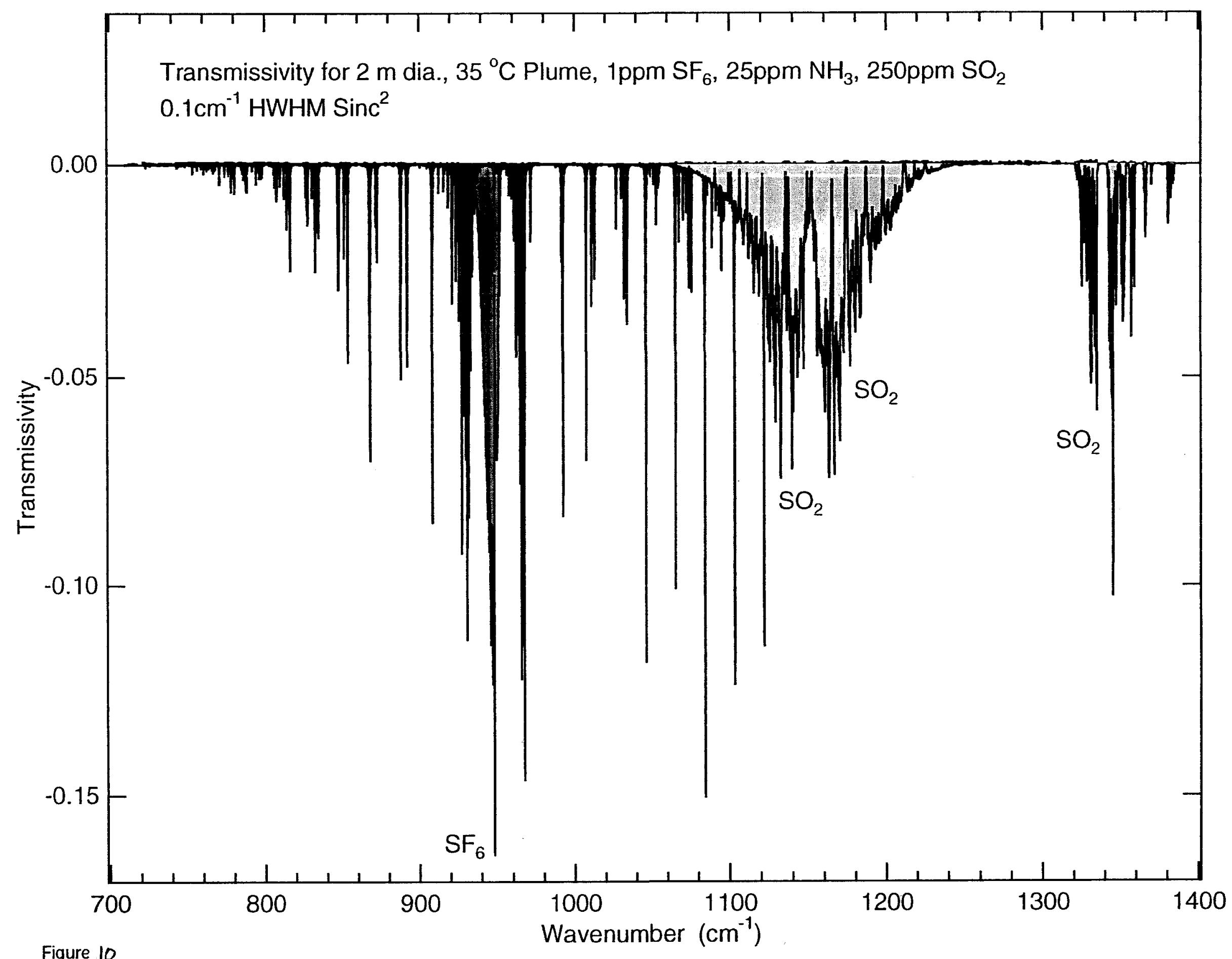




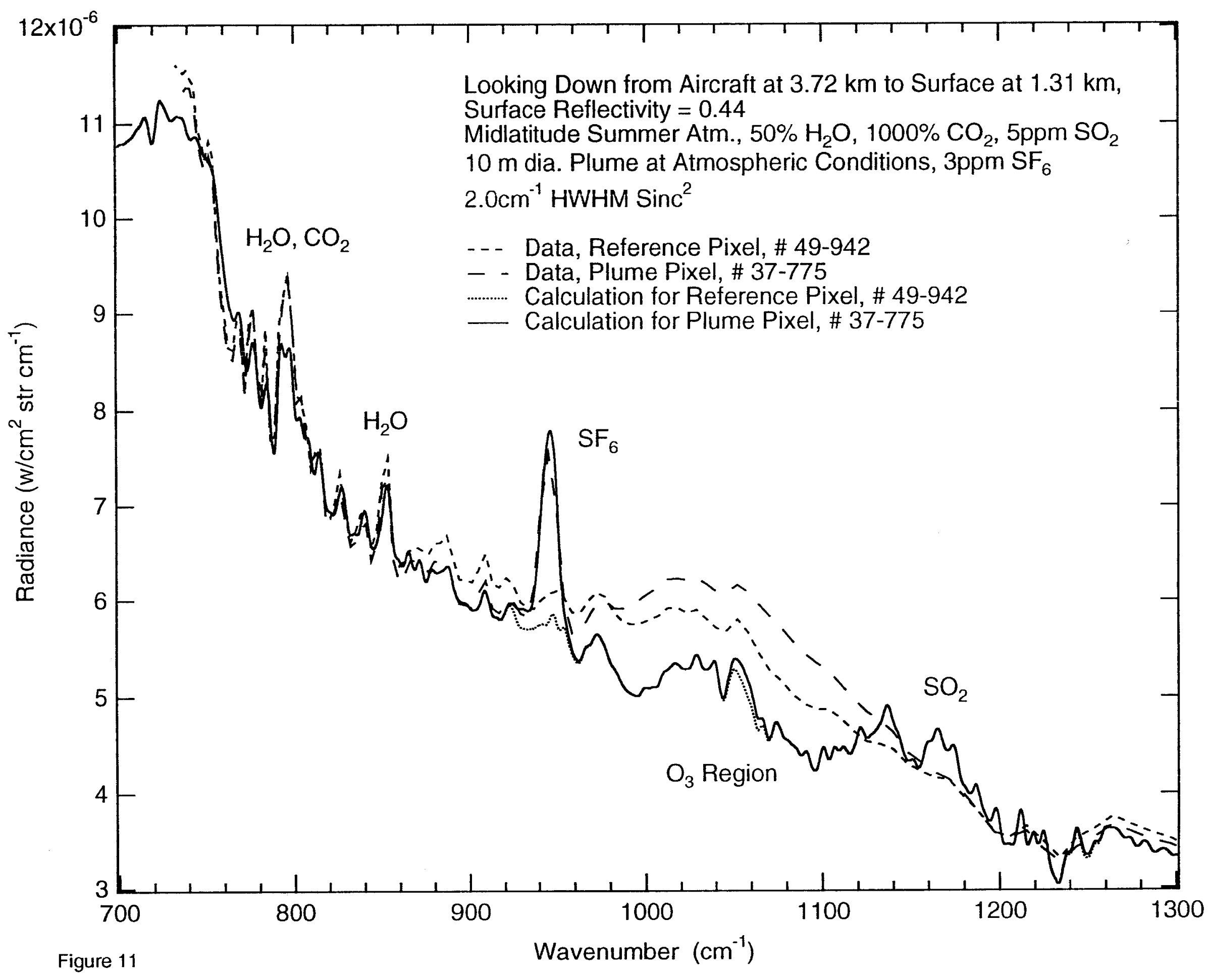




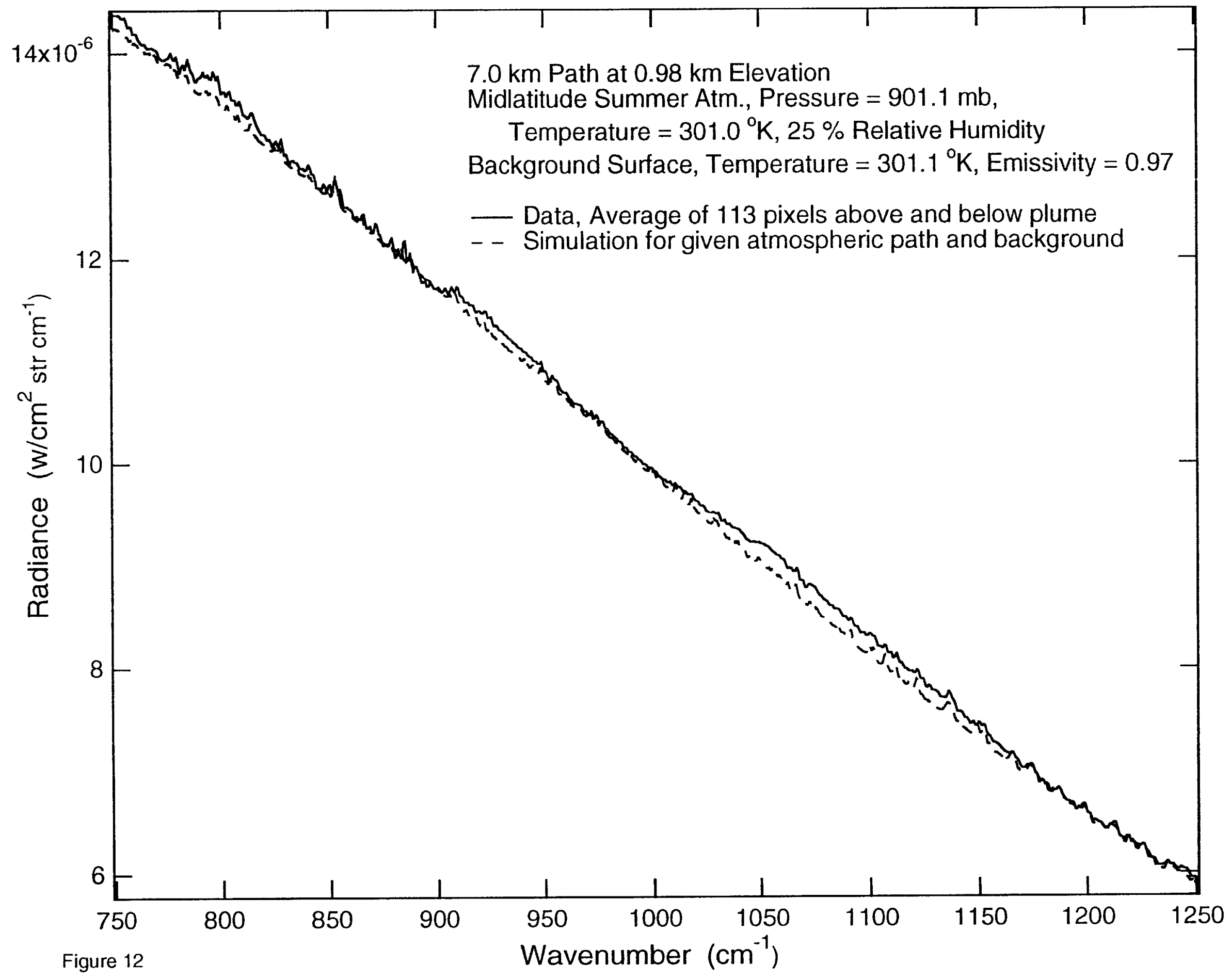




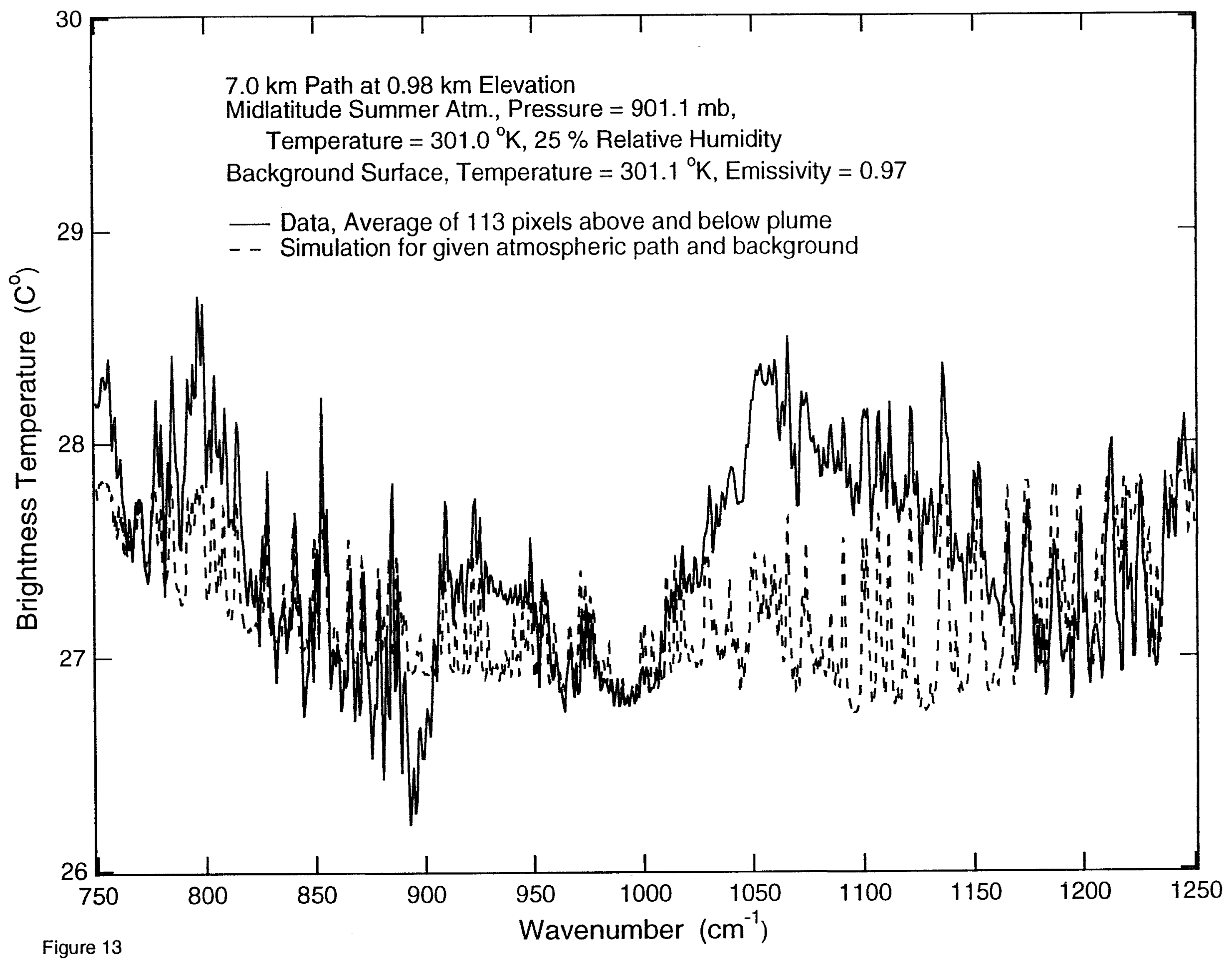




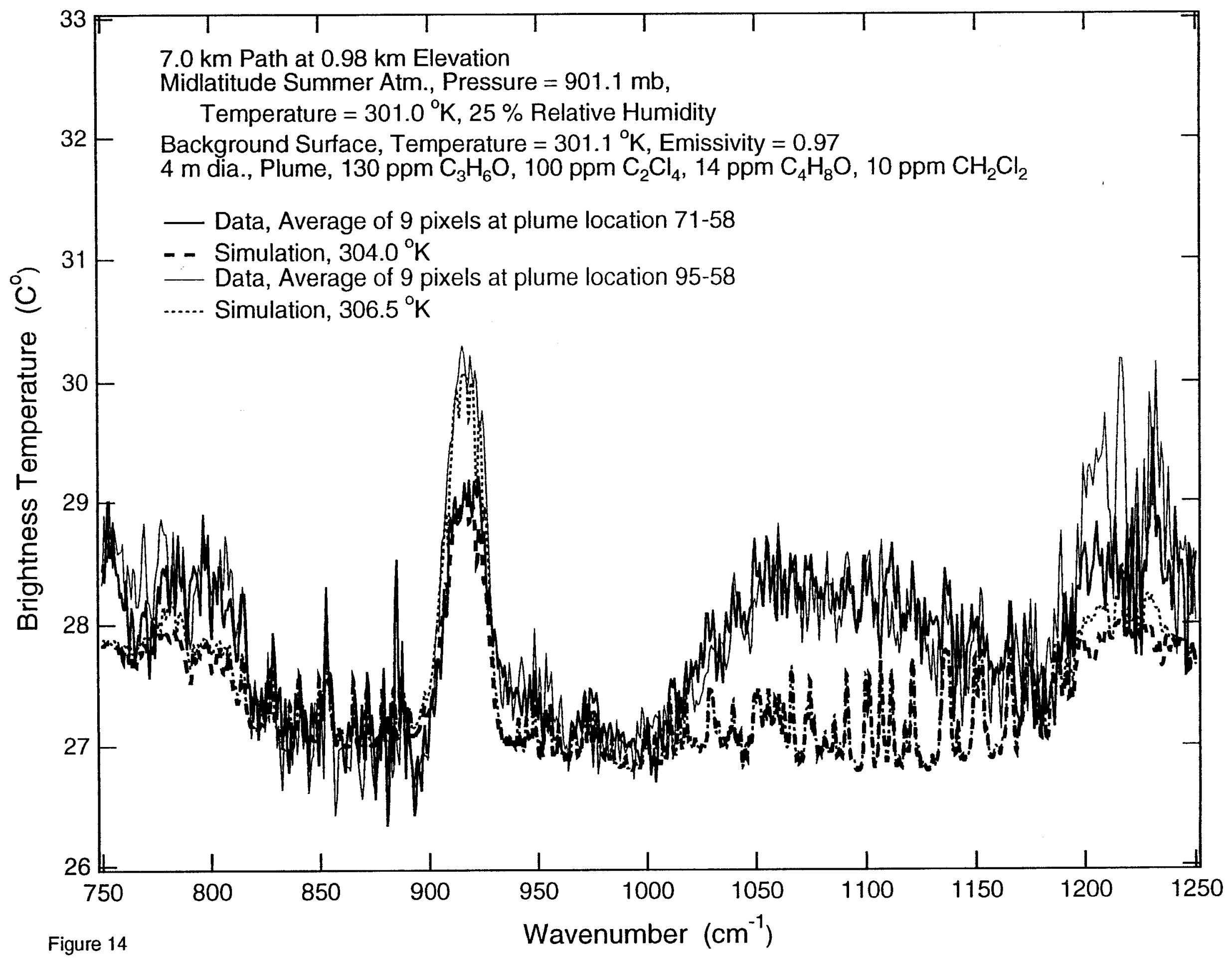




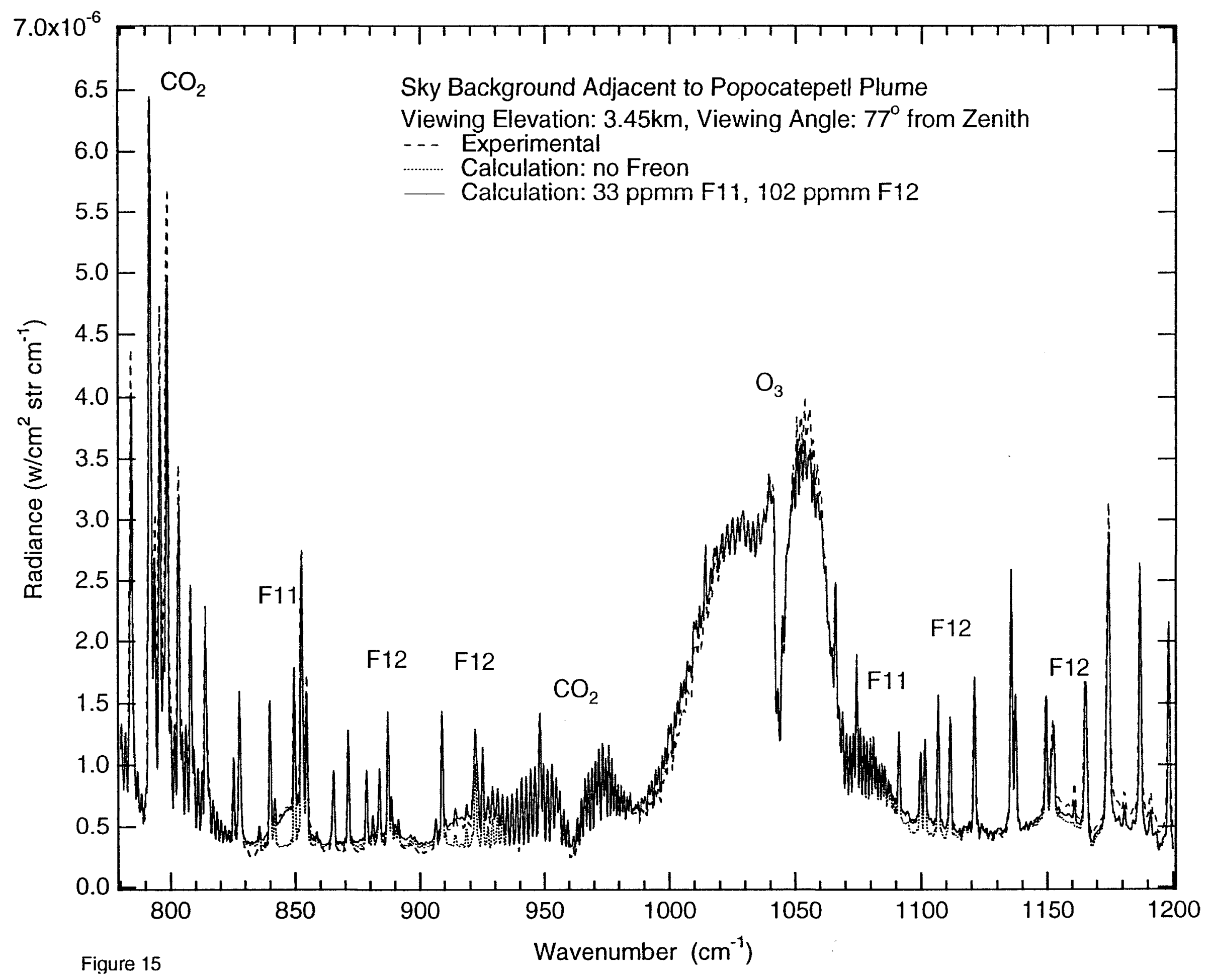




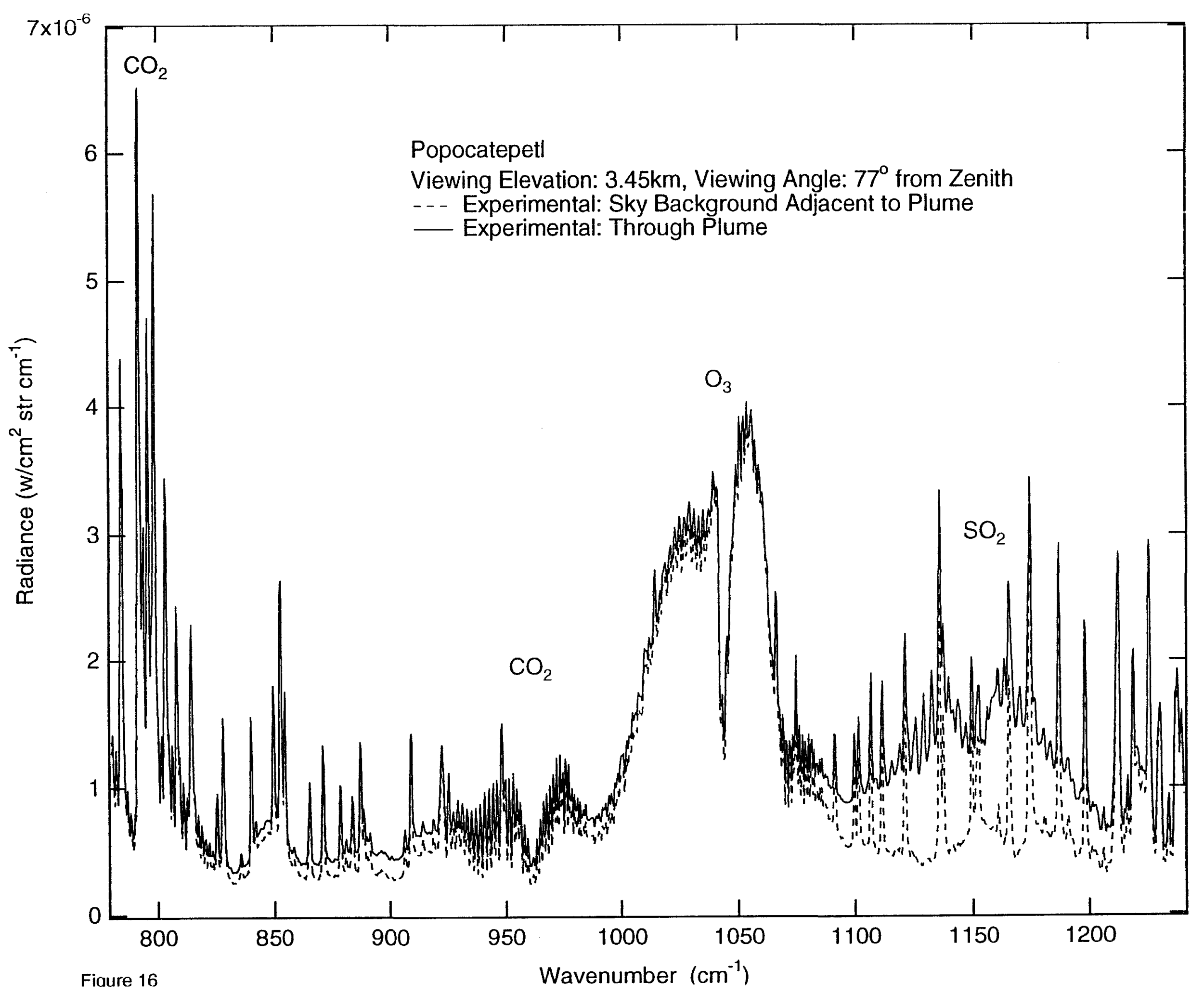




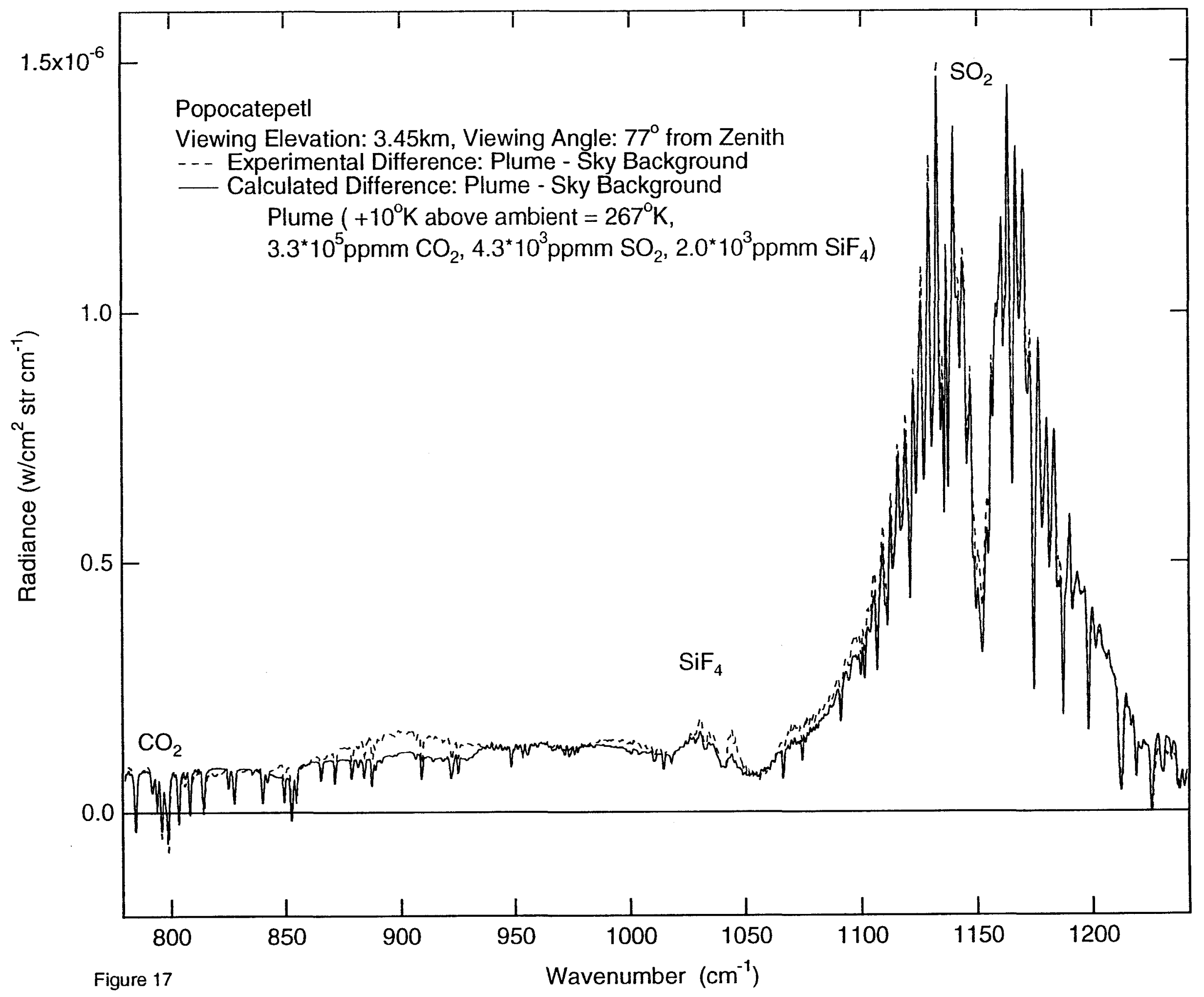



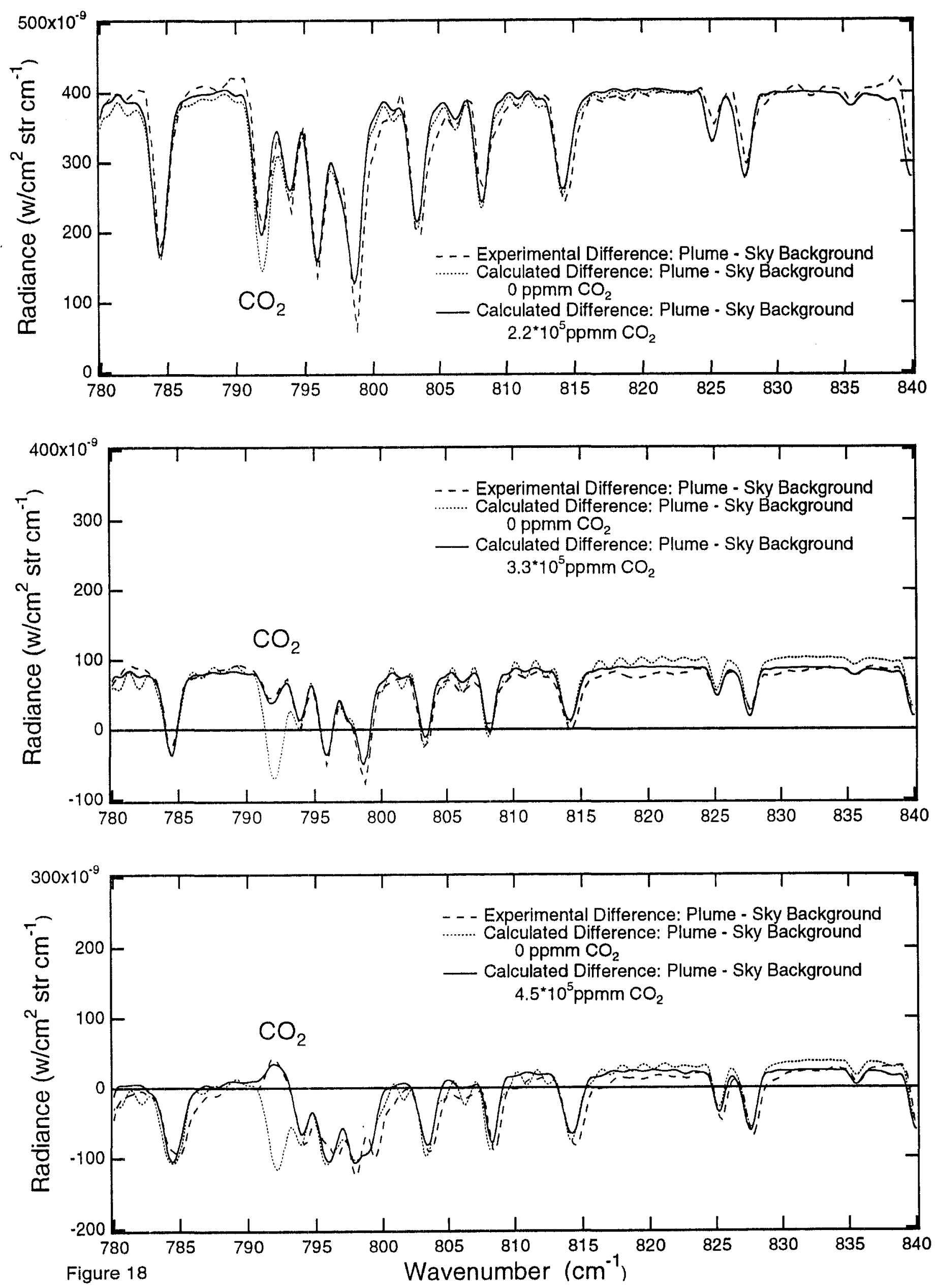

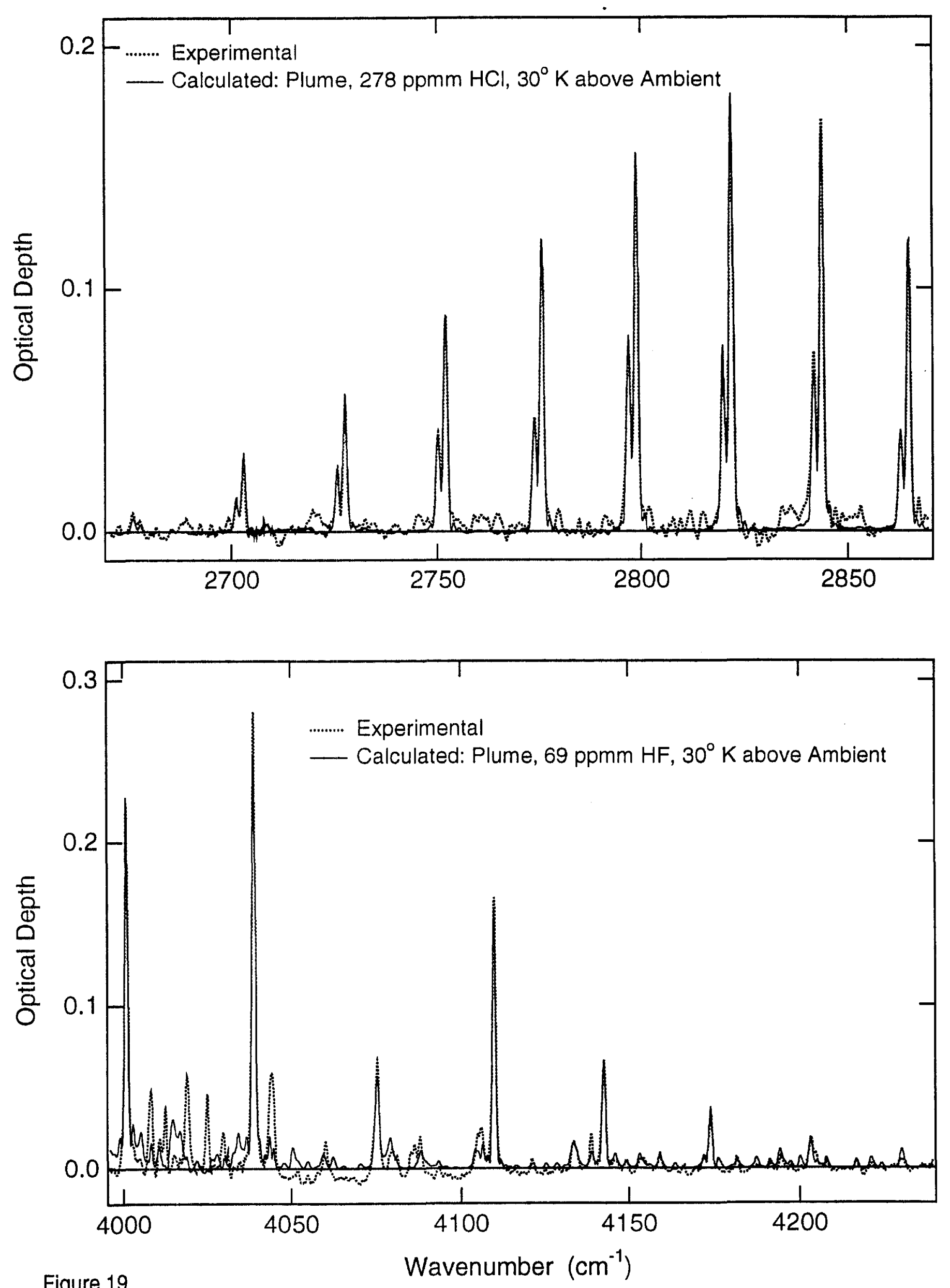